\title{
An Adaptive Fault Current Limiting Control for MMC and Its Application in DC Grid
}

\author{
Binye Ni, Wang Xiang, Member, IEEE, Meng Zhou, Wenping Zuo, Wei Yao, Senior Member, IEEE, \\ Weixing Lin, Member, IEEE, Jinyu Wen, Member, IEEE
}

\begin{abstract}
This paper proposes an adaptive fault current limiting control (AFCLC) for modular multilevel converters (MMC). Without introducing extra current limiting devices, this control scheme enables fast fault current suppression during DC faults. The AFCLC will be triggered automatically once DC faults occur. By adaptively reducing the output DC voltages of MMCs, the fault current can be suppressed. Compared with the existing current limiting methods, the proposed AFCLC has a better performance on fault current limiting, since it only depends on the real-time operating condition and no fault detection delay is imposed. Firstly, the principle of the proposed AFCLC together with the mathematical analysis is disclosed. Then, the sensitivity analysis of the impact of key control parameters on the current limiting effect is investigated. Finally, the effectiveness of AFCLC is demonstrated in a four-terminal HVDC grid test model. The simulation results show that the proposed AFCLC can reduce the interrupted current and energy absorption of a DCCB from 10.39 $\mathrm{kA}$ and 38.24 MJ to 4.62 $\mathrm{kA}$ and $8.32 \mathrm{MJ}$, respectively. The simulation results also prove that the AFCLC will not affect the accuracy of the DC fault detection algorithms under DC faults.
\end{abstract}

Index Terms - modular multilevel converters (MMC), DC grid, DC circuit breaker (DCCB), DC fault, HVDC transmission.

\section{INTRODUCTION}

Due to the advantages of self-commutation and decoupling control of active and reactive power, the modular multilevel converter (MMC) based DC grid technology is widely recognized as a promising approach for large-scale renewable energy integration over long-distance [1]-[4]. To deal with the short-circuit faults on cables or overhead lines, the DC circuit breakers (DCCB) are adopted to isolate the faulty lines [5][6]. However, due to the low impedance of the DC grid, the fault currents rise rapidly and thus impose high interrupted current, energy absorption and breaking time requirements on the DCCBs, leading to the high cost of DCCBs. Taking the Zhangbei project as an example [7], it adopts $450 \mathrm{mH}$ current-limiting inductors to avoid blocking of MMCs during DC faults. However, the maximum fault current that needs to be interrupted is as high as $25 \mathrm{kA}$ [8]. Moreover, the gross investment of DCCBs exceeds $60 \%$ of that of the converters

This work is sponsored by the National Natural Science Foundation of China (51807071), the Joint Funds of the National Natural Science Foundation of China (U1766211) and the China Postdoctoral Science Foundation (2018M642840). (Corresponding author: Wang Xiang)

B. Ni, M. Zhou, W. Zuo, W. Yao, J. Wen are with the State Key Laboratory of Advanced Electromagnetic Engineering and Technology, Huazhong University of Science and Technology, Wuhan 430074, China. (e-mail: nibinye@foxmail.com, zhoumeng4077@ foxmail.com,w.yao@ hust.edu.cn, radio.zuo@foxmail.com, jinyu.wen @ hust.edu.cn).

W. Xiang is with the Department of Electronic and Electrical Engineering, University of Strathclyde, Glasgow, G1 1XW, U.K. (e-mail: xiangwang1003@ foxmail.com).

W. Lin is with the TBEA SunOasis Co., Ltd, Urumchi 830011, Xinjiang, China. (e-mail: weixinglin@foxmail.com).
[9], which hinders the development of the DC grid.

To reduce the cost of $\mathrm{DCCB}$, a common method is to increase the inductance of DC inductors [10][11]. However, larger inductance may not only increase the total cost of the DC grid, but also result in the instability problem [12]. A feasible alternative is to use the fault current limiter to increase the impedance in the circuit [13][14].

Another option to limit the fault current is to use the controllability of converters. Many DC fault current limiting control schemes are proposed for the full-bridge MMC (FB-MMC) and the hybrid MMC based on mixed full-bridge sub-modules (FBSMs) and half-bridge sub-modules (HBSMs). Reference [15] proposed a DC fault ride-through strategy of the hybrid MMC based on the balancing control of arm capacitor energies. References [16] and [17] proposed the DC current control loop associated with the DC modulation index to decouple the AC and DC voltages. That enables the hybrid MMC to actively control the DC fault current. In [18], the feedforward DC line voltage control is used to optimize the DC current control loop and accelerate its response to DC faults. It is also validated in [19] that the full-bridge MMC can actively control the fault current, reducing the interruption energy of DCCB. Reference [20] proposed the methods of controlling the converter current or line current to zero to interrupt the fault current without implementing DCCBs for a four-terminal meshed DC grid.

The aforementioned fault current control schemes are all benefiting from the negative voltage output capabilities provided by the FBSMs. However, the utilization of FBSMs increase the cost of converters. Recalling the fault analysis in [21] and [22], the high fault current in the DC grid is mainly contributed by the SM capacitors. The fault current can be limited by altering the inserted number of SMs, thus, avoiding the discharge of SM capacitors. The fewer the number of inserted SMs during faults, the less fault current is contributed by the SM capacitors. Thus, some researches redirect to explore the potential control ability of HB-MMC for active fault current limitation. Since the HBSMs cannot output negative voltage, the fault current limiting control schemes for the full-bridge MMC cannot be directly applied to the half-bridge MMCs. A coordination scheme between HB MMCs and DCCBs was proposed in [23] to suppress the DC fault current. When DC faults happen, $\mathrm{HB} \mathrm{MMCs}$ temporarily bypass all $\mathrm{SMs}$ to reduce the DC voltage of the converters during DCCB tripping. In [24], the DC voltage reference in the vector control is decreased to reduce the inserted number of SMs and the DC output voltage.

These approaches of reducing the DC voltages to a certain value are not applicable under all conditions. For example, in 
the case of different fault resistances, it requires different reductions in DC voltages rather than a constant given value. On the other hand, these methods need to be triggered following the command of the DC fault protection system. Due to the detection delay, the fault current rises freely during the detection period.

To overcome the defects of the existing HB MMC fault current limiting methods, this paper proposes an adaptive fault current limiting control (AFCLC) for HB MMC. By adaptively bypassing parts of SMs, this control scheme can reduce the MMC DC output voltages adjusting to different fault resistances. It can suppress the discharge of capacitors in MMC, thus reducing the fault current. Besides, the AFCLC operates immediately without waiting for the command from the protection system, thus achieving better performance on suppressing fault current.

The remainder of this paper is organized as follows. Firstly, the principle of the proposed AFCLC together with its coordination with DCCBs are introduced in Section II. Then, the mathematical analysis of the MMC with the proposed AFCLC is disclosed and the impact of the AFCLC parameters on fault current limitation performance is analyzed in Section III. The simulation of a four-terminal meshed DC grid applying the proposed AFCLC is performed in Section IV to verify its effectiveness. Besides, the performance of the system with the AFCLC is evaluated in Section V. Finally, the conclusion is drawn in Section VI.

\section{The AdAPtive FAult CurRent Limiting CONTROL}

\section{A. Principle of the Proposed AFCLC}

Referring to the existing methods of altering the number of the inserted SMs [23]-[25], the general fault current limiting concept based on DC voltage reducing is concluded in Fig. 1. It introduces a modulation factor $K_{M}$ and makes the number of the inserted SMs of each arm unit become $K_{M} N_{p(n)}$. Therefore, the DC output voltage of the converter becomes $K_{M} V_{d c n}$, wherein $V_{d c n}$ is the rated DC voltage of the DC grid. In normal operation, the modulation factor $K_{M}$ equals 1.0. In fault conditions, the modulation factor $K_{M}$ decreases within the range of $0 \leq K_{M}<1$ to reduce the inserted SM number and the DC voltage of the converter, thereby suppressing the fault current. In some existing publications [23]-[24], all the sub-modules are bypassed, indicating that $K_{M}$ equals 0 .

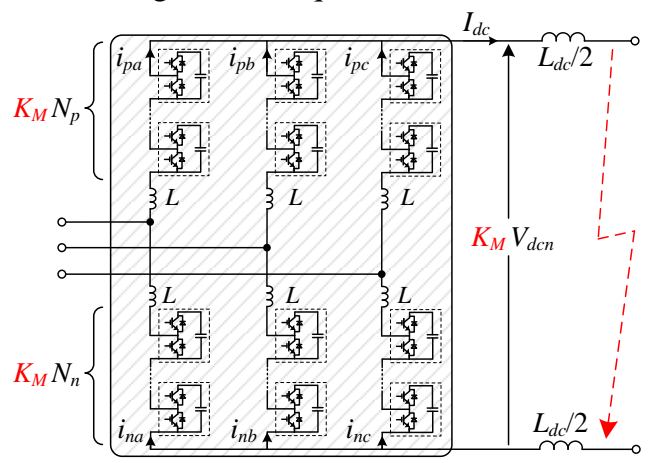

Fig. 1 Illustration of general fault current limiting methods.

In this paper, the value of modulation factor $K_{M}$ is determined by the AFCLC. The diagram of the proposed
AFCLC is depicted in Fig. 2, which can be divided into two parts, the adaptive current controller and the adaptive voltage limiter. $K_{\mathrm{M}}$ can be calculated as:

$$
K_{M}=1-K_{P}\left(I_{d c}-I_{d c-s e t}\right)-K_{D} \frac{\mathrm{d} I_{d c}}{\mathrm{~d} t}
$$

where $I_{d c}$ is the DC current; $K_{P}$ and $K_{D}$ are the scale and differential factors of the controller. $I_{d c \text {-set }}$ is the set point of the DC current of the converter. The schematic diagram to generate $I_{d c \text {-set }}$ is shown in Fig. 3 (a). For the converters controlling the active power, the set current $I_{d c \text {-set }}$ is calculated by the reference power. For the converters controlling the DC voltage, $I_{d c \text {-set }}$ is generated by sampling $I_{d c}$ in a period of $100 \mathrm{~ms}$. The derivative term is implemented by using a sampling element with sampling period of $200 \mu \mathrm{s}$. Besides, a hysteresis comparator is used in the derivative term to avoid mal-operation in normal operation, as shown in the left bottom of Fig. 2. The activation threshold is normally set as half of the changing rate of the fault current $\left(V_{d c} / 4 L_{d c}\right)$, and the return threshold is 0 . The upper and lower limits of the adaptive current controller are 1.0 and $K_{\text {min }}$, respectively. The lower limit $K_{\min }$ is determined by the adaptive voltage limiter. The inputs of this limiter $\left(V_{\text {line }}, V_{\text {line } 2}, \ldots, V_{\text {line } \mathrm{N}}\right)$ are the DC voltages of the transmission lines that connect to the converter, as shown in Fig. 3 (b). The adaptive voltage limiter divides the minimum value of these line voltages by the rated DC voltage $V_{d c n}$ to get $K_{\text {min }}$.

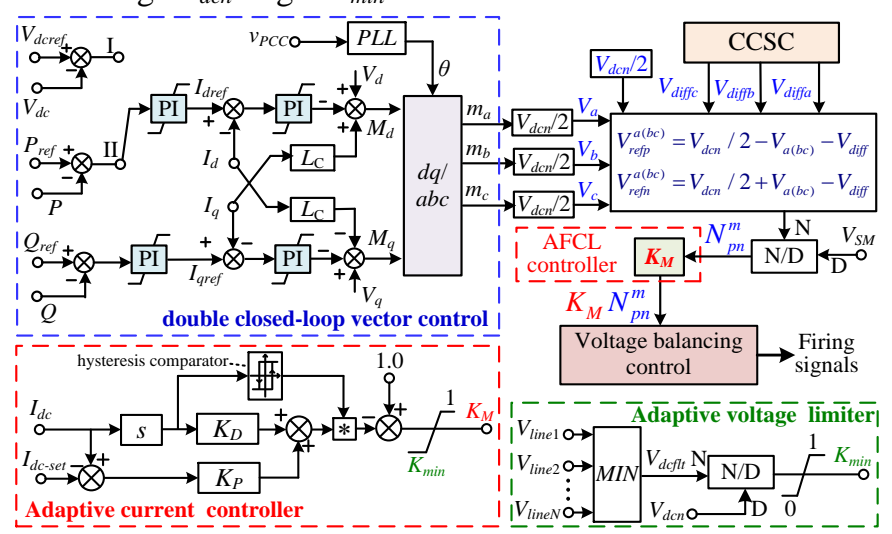

Fig. 2 The diagram of the adaptive fault current limit control.

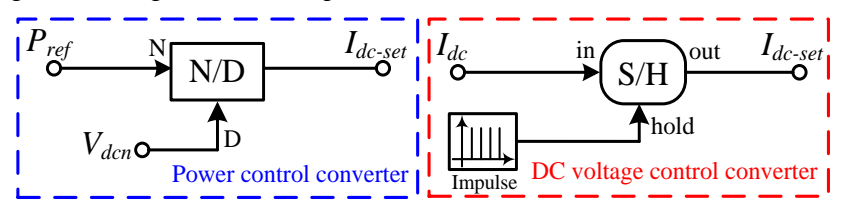

(a) Generation of $I_{d c \text {-set }}$ for different converters

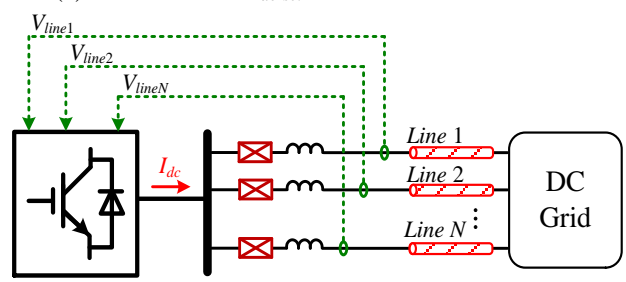

(b) Measurements of the DC current and line voltages

Fig. 3 Generation of $I_{d c \text { set }}$ and measurement of DC line voltages

In normal operation, the DC current $I_{d c \text {-set }}$ maintains at the rated value and the DC line voltages approximately equal to $V_{d c n}$. Therefore, $K_{M}$ remains 1.0 without interrupting the operation of the converter. Once a short-circuit fault occurs, the 
DC current $I_{d c}$ rises rapidly and the voltage of the fault line decreases immediately. Thus, $K_{M}$ reduces, as shown in the equation (1), to suppress the fault current.

The sequence of DC fault protection and AFCLC triggering is shown in Fig. 4. After the fault occurs, the traveling wave induced from the fault point will propagate through the transmission lines. Once it arrives at the line terminals, the DC fault protection algorithm will be activated. Meanwhile, the line voltage $V_{\text {line } 12}$ decreases and the converter current $I_{d c 1}$ rises. Thus, the hysteresis comparator is triggered and the AFCLC is enabled. Then, the AFCLC operates to reduce the DC output voltage of MMC. Since the AFCLC starts later than the arrival of the traveling wave, it will not affect the detection of the traveling wave head. Besides, the reduction of MMC output voltage caused by the AFCLC is far slower than that resulting from the DC fault traveling wave. Therefore, the AFCLC has little effect on the traveling wave based DC fault detection algorithms.

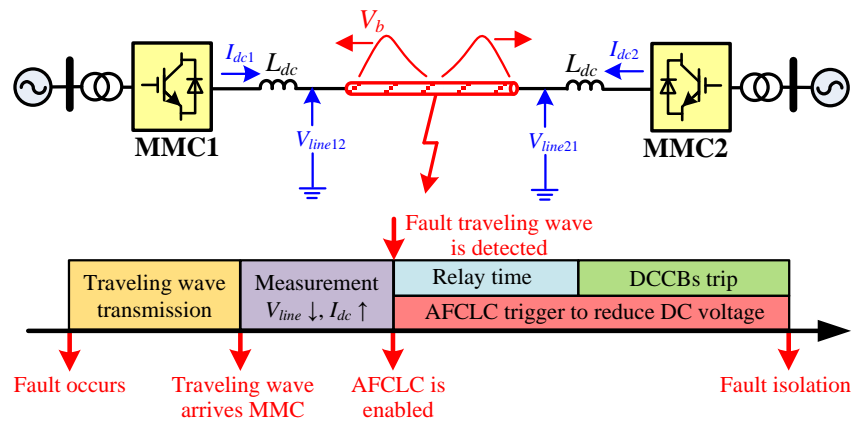

Fig. 4 The sequence of fault detection and AFCLC triggering.

\section{B. Coordination of AFCLC and DCCBs}

The flowchart of the coordination scheme between AFCLC and DCCB is shown in Fig. 5. The activation of AFCLC is independent of the fault protection system. Once a fault occurs, it is triggered automatically to limit the fault current. Due to the current limiting effect provided by the AFCLC, the fast fault protection and strict DCCB tripping requirement are mitigated. Subsequent to receiving the isolation information from DCCBs, the AFCLC exits operation, and the DC voltages will be recovered.

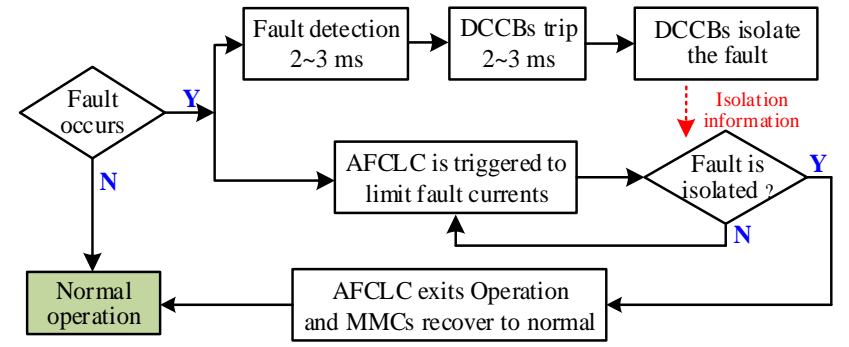

Fig. 5 Flowchart of coordination of AFCLC and DCCBs.

\section{Current Limiting Principle of AFCLC}

\section{A. Fault Currents Analysis of MMC Employing AFCLC}

A mathematical model is used to analyze the fault current of MMC employing the proposed AFCLC. To simplify the calculation, the equivalent arm capacitors are approximated by voltage sources. The equivalent circuit of the MMC with
AFCLC is shown in Fig. 6, wherein $L_{a c}$ and $R_{a c}$ are the AC system inductance and resistance, respectively. $L_{a r m}$ is the arm inductance. $R_{a r m}$ is the equivalent arm resistance that equals to the sum of the switching-on resistance of the IGBTs in each arm. $L_{d c}$ and $R_{d c}$ are the inductance and resistance of the DC side, respectively. $R_{f}$ is the fault resistance. $v_{p(n) j}$ and $i_{p(n) j}$ are voltage and current of the upper(lower) arm of phase $j$, and $v_{j}$ is the AC grid voltage of phase $j$, where " $j$ " represents phases $a, b$, $c$.

According to the superposition theorem, the equivalent circuit shown in Fig. 6 can be further divided into a DC equivalent circuit and an $\mathrm{AC}$ equivalent circuit. These equivalent circuits are shown in Fig. 7 and Fig. 8, where $v_{d c-j}$ and $v_{a c-j}$ are the $\mathrm{DC}$ and $\mathrm{AC}$ components of arm voltages, respectively. The expressions of $v_{d c-j}$ and $v_{a c-j}$ are as follows:

$$
\left\{\begin{array}{l}
v_{d c-j}=v_{p j}+v_{n j}=K_{M} V_{d c n} \\
v_{a c-j}=\frac{v_{p j}-v_{n j}}{2}=K_{M} V_{a r m} \cos \left(\omega t+\alpha_{j}\right)
\end{array}\right.
$$

where $V_{a r m}$ and $\alpha_{j}$ are the amplitude and initial phase of $v_{a c-j}$, respectively.

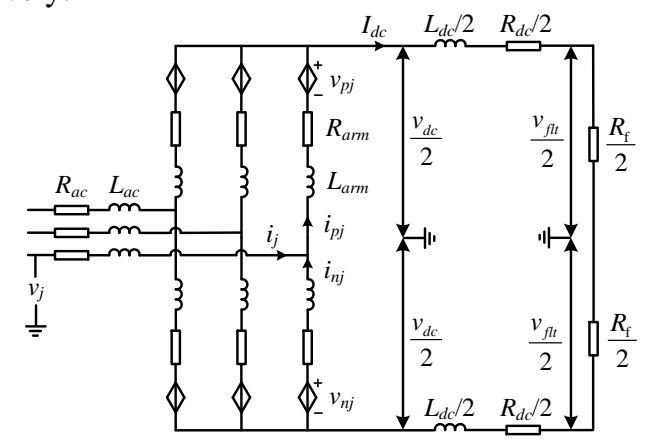

Fig. 6 Equivalent circuit of MMC employing the AFCLC.

1) DC current

According to the DC equivalent circuit shown in Fig. 7, the differential equation of $I_{d c}$ is as follows:

$$
\frac{\mathrm{d} I_{d c}}{\mathrm{~d} t}+\frac{R_{e q 1}}{L_{e q 1}} I_{d c}=\frac{v_{d c-j}}{L_{e q 1}}=\frac{K_{M} V_{d c n}}{L_{e q 1}}
$$

where $L_{e q 1}$ and $R_{e q 1}$ are the total inductance and resistance of the DC equivalent circuit and are given as:

$$
L_{e q 1}=L_{d c}+\frac{2}{3} L_{a r m}, R_{e q 1}=R_{d c}+R_{f}+\frac{2}{3} R_{a r m}
$$

Combining equation (1) and (3), we have

$$
\frac{\mathrm{d} I_{d c}}{\mathrm{~d} t}+\frac{R_{e q 1}+K_{P} V_{d c n}}{L_{e q 1}+K_{D} V_{d c n}} I_{d c}=\frac{\left(1+K_{P} I_{d c-s e t}\right) V_{d c n}}{L_{e q 1}+K_{D} V_{d c n}}
$$

Assuming a fault occurs at $t=0$. The solution of (5) is

$$
I_{d c}=\left(I_{d c-s e t}-I_{s}\right) e^{-\frac{t}{\tau_{d c}}}+I_{s}
$$

where $I_{s}$ is the steady-state DC current of $I_{d c} . \tau_{d c}$ is the time constant of the DC equivalent circuit.

$$
\begin{gathered}
I_{s}=\frac{\left(1+K_{P} I_{d c-s e t}\right) V_{d c n}}{R_{e q 1}+K_{P} V_{d c n}} \\
\tau_{d c}=\frac{L_{e q 1}+K_{D} V_{d c n}}{R_{e q 1}+K_{P} V_{d c n}}
\end{gathered}
$$




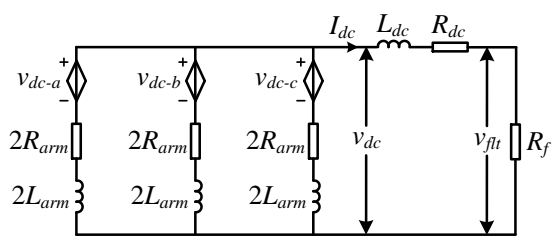

Fig. 7 DC equivalent circuit of MMC.

From equations (6)-(8), it is obvious that the proposed AFCLC can limit the DC fault current to a low steady-state value and decrease the current rising rate. The steady-state current is related to $K_{P}$. The current rising rate is associated with $K_{P}$ and $K_{D}$. The DC fault current can be suppressed by configuring the reasonable parameters of the AFCLC.

2) AC side and arm currents

The equivalent resistance and inductance of the $\mathrm{AC}$ equivalent circuit shown in Fig. 8 are

$$
\begin{aligned}
& R_{e q 2}=R_{a c}+\frac{R_{a r m}}{2}, L_{e q 2}=L_{a c}+\frac{L_{a r m}}{2}
\end{aligned}
$$

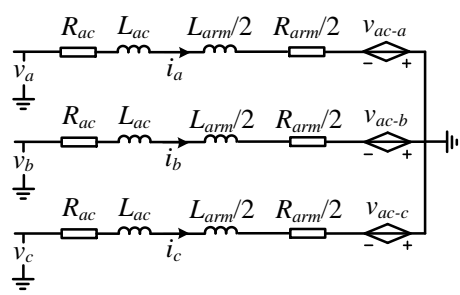

Fig. 8 AC equivalent circuit of MMC.

Assuming the amplitude and initial phase of $v_{j}$ are respectively $V_{a c}$ and $\beta_{j}$, which can be obtained by measuring the operation of the system, we have

$$
v_{j}=V_{a c} \cos \left(\omega t+\beta_{j}\right)
$$

According to the equivalent circuit shown in Fig. 8 and the expressions of $v_{a c-j}$ and $v_{j}$, the differential equation of the AC side current $i_{j}$ is as follows

$$
\frac{\mathrm{d} i_{j}}{\mathrm{~d} t}+\frac{R_{e q 2}}{L_{e q 2}} i_{j}=\frac{K_{M} V_{a r m}}{L_{e q 2}} \cos \left(\omega t+\alpha_{j}\right)+\frac{V_{a c}}{L_{e q 2}} \cos \left(\omega t+\beta_{j}\right)
$$

According to equations (1) and (6), the modulation factor $K_{M}$ is represented as:

$$
K_{M}=1+K_{P}\left(I_{d c-s e t}-I_{s}\right)+\left(K_{D} / \tau_{d c}-K_{P}\right)\left(I_{d c-s e t}-I_{s}\right) e^{-\frac{t}{\tau_{d c}}}
$$

Combining equations (11) and (12), the differential equation of $i_{j}$ can be solved. Assuming a fault occurs at $t=0$, the AC current after fault occurrence can be expressed as:

$$
i_{j}(t)=i_{j}^{+}(t)+\left[i_{j}^{-}(0)-i_{j}^{+}(0)\right] e^{-\frac{t}{\tau_{a c}}}
$$

where "-" denotes the steady-state operating condition before fault occurrence and "+" denotes the operating condition after fault occurrence. $\tau_{a c}=L_{e q 2} / R_{e q 2}$, is the time constant of the $\mathrm{AC}$ equivalent circuit. The expressions of $i_{j}^{-}$and $i_{j}^{+}$are

$$
\begin{aligned}
i_{j}^{-}= & \frac{V_{a c} \cos \left(\omega t+\beta_{j}-\delta\right)}{\sqrt{R_{e q 2}^{2}+\left(\omega L_{e q 2}\right)^{2}}}+\frac{V_{a r m} \cos \left(\omega t+\alpha_{j}-\delta\right)}{\sqrt{R_{e q 2}^{2}+\left(\omega L_{e q 2}\right)^{2}}} \\
i_{j}^{+}= & I_{1} \cos \left(\omega t+\beta_{j}-\delta\right)+I_{2} \cos \left(\omega t+\alpha_{j}-\delta\right) \\
& +I_{3} \cos \left(\omega t+\alpha_{j}-\varphi\right)
\end{aligned}
$$

where

$$
\begin{aligned}
& \left\{\begin{array}{l}
\tan \delta=\frac{\omega L_{e q 2}}{R_{e q 2}} \\
\tan \varphi=\frac{\omega L_{e q 2}}{R_{e q 2}-L_{e q 2} / \tau_{d c}}
\end{array}\right. \\
& I_{1}=\frac{V_{a c}}{\sqrt{R_{e q 2}^{2}+\left(\omega L_{e q 2}\right)^{2}}} \\
& I_{2}=\frac{\left[1+K_{P}\left(I_{d c-s e t}-I_{s}\right)\right] V_{a r m}}{\sqrt{R_{e q 2}^{2}+\left(\omega L_{e q 2}\right)^{2}}} \\
& I_{3}=\frac{\left(K_{D} / \tau_{d c}-K_{P}\right)\left(I_{d c-s e t}-I_{s}\right) V_{a r m} e^{-\frac{t}{\tau_{d c}}}}{\sqrt{\left(R_{e q 2}-L_{e q 2} / \tau_{d c}\right)^{2}+\left(\omega L_{e q 2}\right)^{2}}}
\end{aligned}
$$

According to the relationship between DC current, AC currents and arm currents, the expressions of arm currents are:

$$
\left\{\begin{array}{l}
i_{p j}=\frac{I_{d c}}{3}+\frac{i_{j}}{2} \\
i_{n j}=\frac{I_{d c}}{3}-\frac{i_{j}}{2}
\end{array}\right.
$$

The detailed expressions can be obtained by substituting equations (6) and (13) into (20).

\section{B. Verification of Effectiveness of the Proposed AFCLC}

To illustrate the effectiveness of the proposed AFCLC and verify the mathematical analysis presented in the previous sub-section, a tested MMC converter is built in PSCAD. The parameters of the test circuit are shown in Table I. The parameters of the converter are the same as that of MMC1 in Table II. A permanent metallic short-circuit fault is applied at 4 $\mathrm{s}$ at the DC terminal of the converter. Besides, to verify the effect of the AFCLC in a longer time scale, it is assumed that the MMC does not block and the DCCB does not trip during the fault. The parameters of the AFCLC are set as: $K_{P}=0.6, K_{D}=$ 0.0003 .

\begin{tabular}{ccc} 
Table I Parameters of circuit of one-terminal & MMC system \\
\hline Parameter & Symbol & Value \\
\hline Fault resistance & $R_{f}$ & $0.01 \Omega$ \\
AC resistance & $R_{a c}$ & $0.1 \Omega$ \\
AC inductance & $L_{a c}$ & $0.1 \mathrm{H}$ \\
DC resistance & $R_{d c}$ & $2 \Omega$ \\
DC inductance & $L_{d c}$ & $0.2 \mathrm{H}$ \\
\hline
\end{tabular}

Fig. 9 shows the fault current characteristics of the MMC employing the proposed AFCLC. The blue solid line shows the simulation results and the calculation results shown with a dash-dotted line are obtained by equations (6), (13) and(20). As can be seen, the results show a good agreement, which verifies the mathematical analysis presented in the previous sub-section. The DC current increases to the maximum value of $3.22 \mathrm{kA}$ within $6 \mathrm{~ms}$ and then stays steady, which illustrates the effectiveness of the proposed AFCLC. 


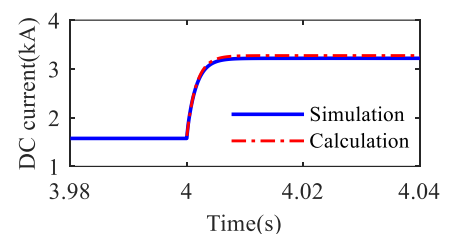

(a) DC current of MMC

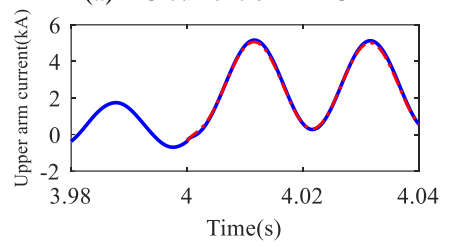

(c) Upper arm current of phase A

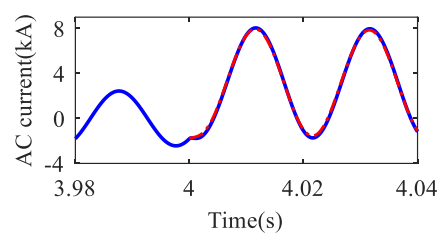

(b) AC current of phase A

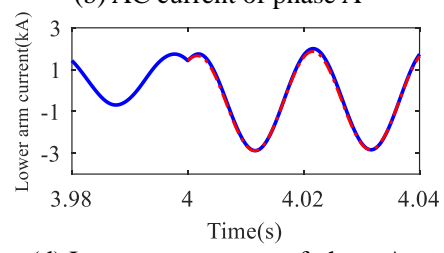

(d) Lower arm current of phase A

Fig. 9 Fault currents of the MMC employing the proposed AFCLC.

\section{Analysis of the Arm Currents during Fault Limit Control}

The proposed AFCLC also has effect on reducing the arm current during fault limit control. The equations (6), (13) and (20) can be used to calculate the arm current with the AFCLC. As for the case of no current-limiting control, the expression of the DC current can be obtained by setting $K_{P}$ and $K_{D}$ to be zero:

$$
I_{d c-n o r m a l}=\left(I_{d c-s e t}-\frac{V_{d c n}}{R_{e q 1}}\right) e^{-\frac{R_{e q 1}}{L_{e q 1}} t}+\frac{V_{d c n}}{R_{e q 1}}
$$

Due to the effect of the vector control of the MMC, the AC components in arm voltages $\left(v_{a c-j}\right)$ has little change during fault limit control. Therefore, the AC current without current limiting control does not change after fault occurs. It can be expressed as:

$$
i_{j-\text { normal }}(t)=i_{j}^{-}(t)
$$

Similar to Section III.B, a single-terminal MMC is used to calculate the maximum arm current. The parameters of the converter are the same as that of MMC2 in Table II. The parameters of the AFCLC are set as the same as that of MMC2 in Table III. A short-circuit fault is applied at $4 \mathrm{~s}$ and the DCCBs tripped at $4.006 \mathrm{~s}$.

The arm currents would reach the peak value when fault is interrupted by the DCCBs at $4.006 \mathrm{~s}$. Since the arm currents are depending on the voltage phases, it is required to cover the range of $(0,2 \pi)$ to obtain the largest arm current during fault isolation. The arm currents at $4.006 \mathrm{~s}$ versus varying phases are calculated, as shown in Fig. 10. It can be observed that the AFCLC reduce the maximum arm current from $4.64 \mathrm{kA}$ to 3.41 $\mathrm{kA}$. Although the AFCLC increase the amplitude of the AC component of the arm current, the DC component are significantly reduced. That results in the reduction in arm current. According to [8], the current of $3.41 \mathrm{kA}$ is acceptable in HVDC applications.

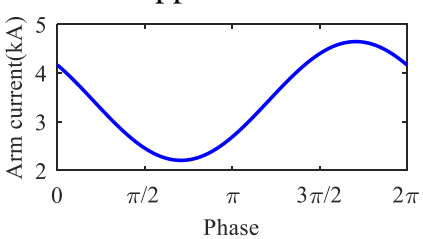

(a) No control

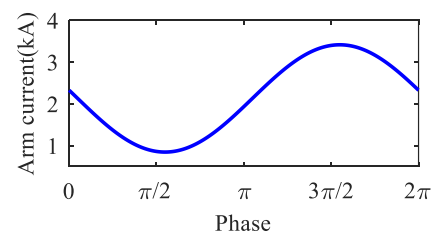

(b) AFCLC
Fig. 10 Calculation results of the arm current at $4.006 \mathrm{~s}$ under different control schemes.

\section{Sensitivity Analysis of Controller Parameters}

According to equations (6)-(8), the characteristics of the DC current are associated with the controller parameters of the AFCLC. To study this relationship, the DC currents of MMC under varying parameters of the AFCLC are shown in Fig. 11.

Fig. 11(a) shows the DC currents of MMC under varying scale factor $K_{P}$. The differential factor $K_{D}$ identically equal to 0 . If $K_{P}=0$, the DC current rises rapidly without limit. Increasing the scale factor $K_{P}$ can significantly suppress the fault current. Fig. 11(b) shows the DC currents under varying differential factor $K_{D}$. The scale factor $K_{P}$ identically equal to 0.3 . It can be observed that increasing the differential factor $K_{D}$ can reduce the rate of current rise. Increasing $K_{P}$ and $K_{D}$ is beneficial to fault current limitation, but may bring about a larger decrease of DC voltages of MMCs during the fault, which means a larger power interruption and a lower AC terminal voltage. There is a trade-off between limiting fault current and mitigating power interruption.

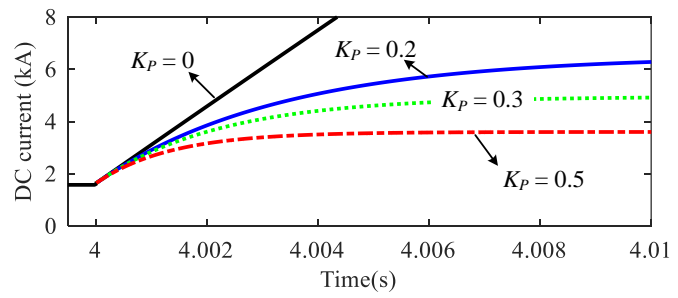

(a) DC currents of MMC under varying $K_{P}$

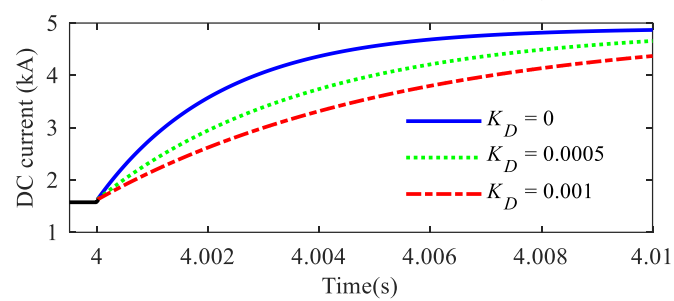

(b) DC currents of MMC under varying $K_{D}$

Fig. 11 DC currents versus varying parameters of AFCLC.

The sensitivity analysis of the AFCLC controller parameters is shown in Fig. 12. Fig. 12 (a) shows the steady-state current $I_{s}$ versus scale factor $K_{P}$. It can be observed that increasing the scale factor $K_{P}$ results in reduced steady-state current $I_{s}$. Besides, decreasing the DC current set-point $I_{d c-\text { set }}$, which represents the operation state of the converter, also causes a reduction in steady-state current $I_{s}$. Fig. 12 (b) shows the time constant $\tau_{d c}$ versus scale factor $K_{P}$. It can be observed that decreasing the scale factor $K_{P}$ results in the increase of the time constant $\tau_{d c}$. Besides, increasing the differential factor $K_{D}$ also leads to an increase in the time constant $\tau_{d c}$. Generally, $K_{P}$ is designed to achieve the $I_{s}$ of less than $2.5\left|I_{d c \text {-set }}\right|$, and $K_{D}$ is designed to ensure the $\tau_{d c}$ of less than $3 \mathrm{~ms}$ (half of the time from fault occurrence to DCCB opening).

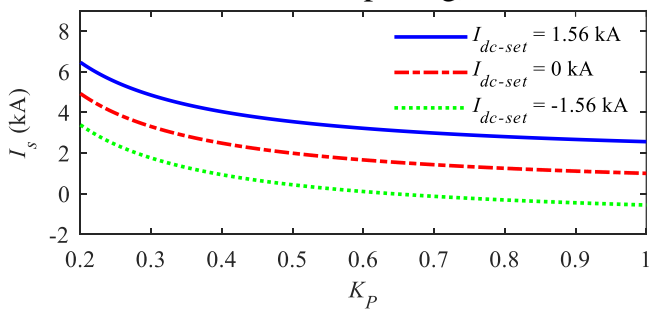

(a) Steady-state current $I_{s}$ versus scale factor $K_{P}$ 
This paper is a post-print of a paper submitted to and accepted for publication in IEEE Transaction on Power Delivery and is subject to Institution of Electrical and Electronic Engineering Copyright. The copy of record is available at IEEE Xplore Digital Library

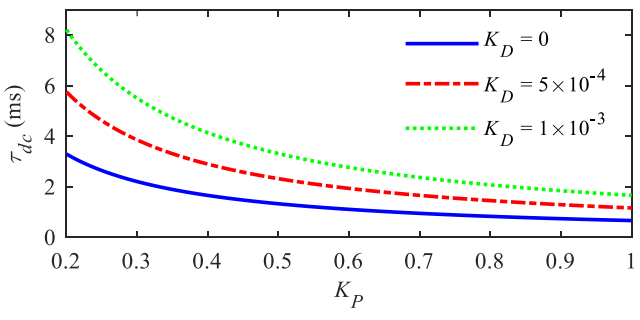

(b) Time constant $\tau_{d c}$ versus scale factor $K_{P}$

Fig. 12 Relationships between the characteristics of DC current and controller parameters.

\section{VERIFICATION OF THE AFCLC IN DC GRID}

To further verify the effectiveness of the proposed AFCLC, a simulation of a four-terminal HVDC grid employing the proposed AFCLC is performed in PSCAD. The structure of this DC grid is shown in Fig. 13. All converters adopt the half-bridge MMC topology. The detailed parameters of the converters are given in Table II. The overhead lines are modeled with the frequency-dependent phase model provided by PSCAD, and the resistance in per unit length of the overhead lines is $0.011 \Omega / \mathrm{km}$. The inductance of the current limiting reactor $L_{d c}$ is $200 \mathrm{mH}$. The DCCBs in this system adopts the hybrid DCCB topology proposed by ABB. The operating time of the ultra-fast disconnector in the DCCB is $3 \mathrm{~ms}$. The relay time of the fault detection algorithm is $3 \mathrm{~ms}$ [26][27].

MMC1, MMC2 and MMC3 operate in active and reactive power control mode to regulate power at 500, 1000 and -500 MW, respectively. MMC4 operates in DC voltage control mode to maintain the DC voltage at $640 \mathrm{kV}$. According to the normal operating state of the converters and equations (7)-(8), the parameters of the AFCLC are set as shown in Table III to achieve the desired steady-state DC current and time constant.

To investigate the effectiveness of the proposed AFCLC in the DC grid, a permanent short-circuit fault $\left(F_{L 23}\right)$ is applied at the head of overhead line 23, as shown in Fig. 13. The fault occurs at $4 \mathrm{~s}$ and the fault resistance is $0.01 \Omega$. There are three schemes being performed for comparison. Scheme 1 represents that the converters operate without current-limiting control (No control). Scheme 2 represents that all converters bypass all SMs once the fault has been detected (Bypass). Scheme 3 represents that the converters adopt the proposed AFCLC. The simulation results are given from Fig. 14 to Fig. 21.

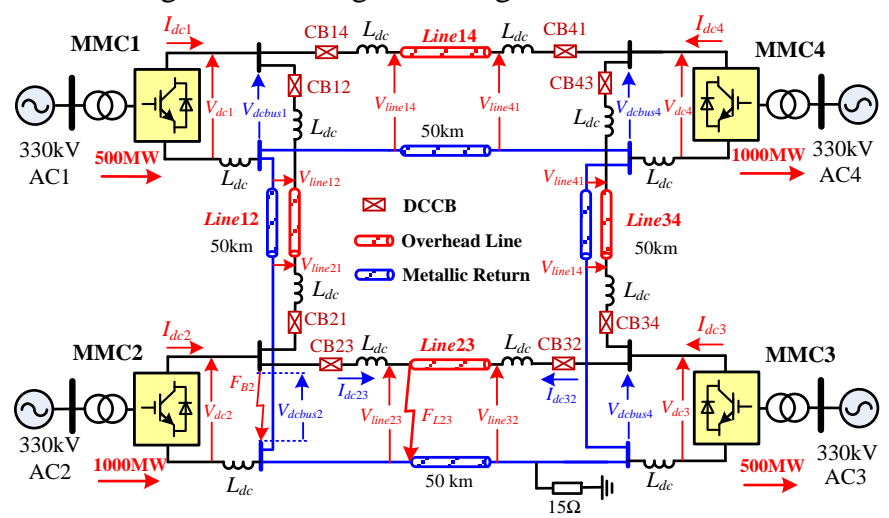

Fig. 13 The structure of the four-terminal DC grid.

Table II Parameters of the Converters in DC Grid

$\begin{array}{llll}\text { Parameters } & \text { MMC1 } & \text { MMC2 } & \text { MMC3 }\end{array}$

\begin{tabular}{ccccc}
\hline Rated capacity (MVA) & 500 & 1000 & 500 & 1000 \\
Rated DC voltage (kV) & 640 & 640 & 640 & 640 \\
AC voltage (kV) & 330 & 330 & 330 & 330 \\
AC inductance (mH) & 0.1 & 0.2 & 0.05 & 0.05 \\
Transformer ratio & $330 / 352$ & $330 / 352$ & $330 / 352$ & $330 / 352$ \\
Transformer Reactance (p.u.) & 0.15 & 0.15 & 0.15 & 0.15 \\
Arm inductance (mH) & 44 & 88 & 44 & 88 \\
Submodule capacitance (mF) & 6.5 & 12 & 6.5 & 12 \\
Submodule number & 200 & 200 & 200 & 200 \\
DC inductance (mH) & 200 & 200 & 200 & 200 \\
Grounding pole resistance $(\Omega)$ & None & None & None & 15 \\
\hline \multicolumn{5}{c}{} \\
\multicolumn{7}{c}{ Table III Parameters of the AFCLC } \\
\hline Parameters & MMC1 & MMC2 & MMC3 & MMC4 \\
\hline$K_{P}$ & 0.363 & 0.509 & 0.357 & 0.279 \\
$K_{D}$ & $4.28 \times 10^{-4}$ & $8.66 \times 10^{-4}$ & $4.11 \times 10^{-4}$ & $1.76 \times 10^{-4}$ \\
$I_{s}(\mathrm{kA})$ & 3.5 & 3.5 & 2 & 2 \\
$\tau_{d c}(\mathrm{~ms})$ & 3 & 3 & 3 & 3 \\
\hline
\end{tabular}

\section{A. Comparisons of Interruption Capacity of DCCBs}

Fig. 14 shows the interrupted currents and absorbed energy of CB23 and CB32. The blue solid line shows the simulation results of Scheme 1. The green dotted line shows the simulation results of Scheme 2. The red dash-dotted line shows the results of Scheme 3. It can be observed that the proposed AFCLC can immediately operate after fault occurrence to suppress the rising fault current, whereas the method of bypassing needs to wait for the delay time caused by the fault detection algorithm. Therefore, the AFCLC can further decrease the fault currents and reduce the interruption capacity than the method of bypassing. Taking CB23 as an example, the AFCLC can reduce the interrupted current from $10.39 \mathrm{kA}$ (No control) and $6.21 \mathrm{kA}$ (Bypass) to $4.62 \mathrm{kA}$, and decrease the absorbed energy from 38.24 MJ (No control) and 14.52 MJ (Bypass) to 8.32 MJ. For $\mathrm{CB} 32$, the AFCLC can reduce the interrupted current from 5.88 $\mathrm{kA}$ (No control) and $3.20 \mathrm{kA}$ (Bypass) to $2.61 \mathrm{kA}$, and decrease the absorbed energy from 16.66 MJ (No control) and 5.83 MJ (Bypass) to 4.69 MJ. This reduction caused by the AFCLC would allow the technical requirements of the DCCBs to be designed at a lower rating, thus reducing the investment of the DCCB. These simulation results demonstrate one of the advantages of the proposed AFCLC.
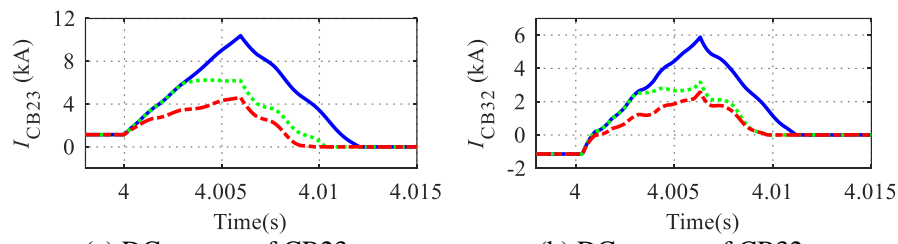

(a) DC current of CB23

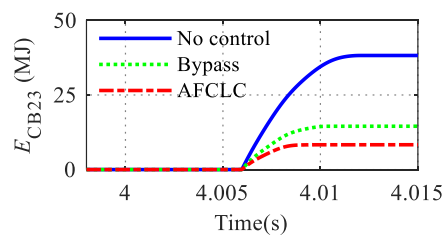

(c) Energy absorption of CB23

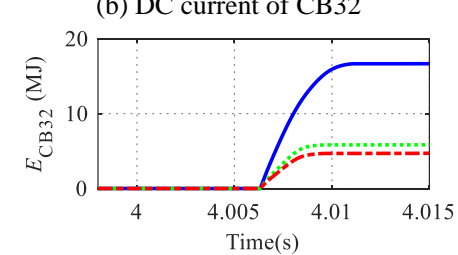

(d) Energy absorption of CB32

Fig. 14 Influence of AFCLC on the technical requirements of DCCBs. 
This paper is a post-print of a paper submitted to and accepted for publication in IEEE Transaction on Power Delivery and is subject to Institution of Electrical and Electronic Engineering Copyright. The copy of record is available at IEEE Xplore Digital Library

\section{B. Comparison of Arm Currents}

Fig. 15 shows the three-phase arm currents of MMC2. The peak values of arm currents in Scheme 1 and Scheme 2 are 4.45 $\mathrm{kA}$ and $4.02 \mathrm{kA}$, respectively, whereas the maximum arm currents in Scheme 3 is decreased to 3.36kA. In Scheme 1, the increase of the arm currents mainly results from a rapidly rising DC current. In Scheme 2, since the converter bypasses all SMs, it is equivalent to a short-circuit fault for the AC system. Hence, the contribution of $\mathrm{AC}$ currents to the arm currents increases. While the proposed AFCLC can not only reduce the DC current, but can also maintain a certain AC voltage to avoid the excessive rise of $\mathrm{AC}$ currents as well as the arm currents. These simulation results illustrate another advantage of the proposed AFCLC.

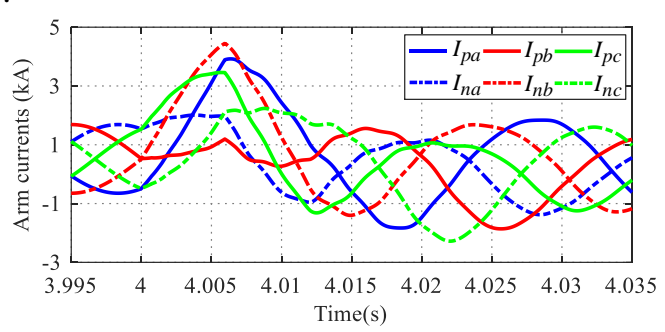

(a) No control

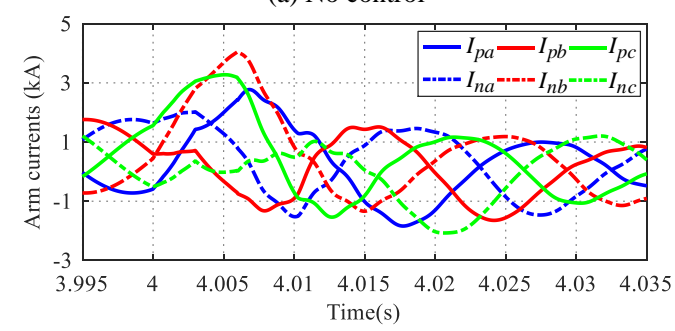

(b) Bypass

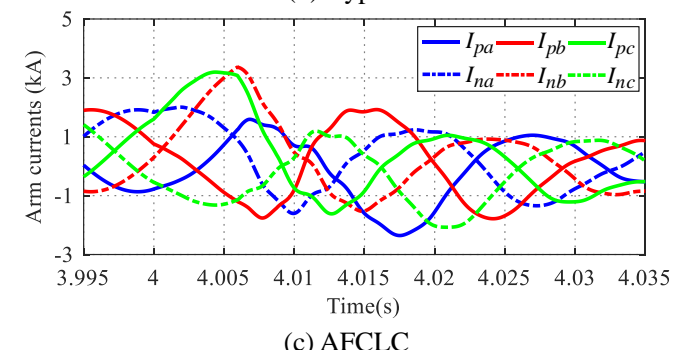

(c) AFCLC

Fig. 15 Comparison of three-phase arm currents in MMC2.

\section{Comparison of Capacitor Voltages}

Fig. 16 shows the average SM capacitor voltages of MMC2. The fault occurs at $4.000 \mathrm{~s}$, and the DCCBs trip at 4.006s. In Scheme 1, the SMs are inserted into the fault circuit. Therefore, the capacitor voltages drop significantly after $4.000 \mathrm{~s}$. In Scheme 2, all SMs are bypassed after 4.003s. Hence, the capacitor voltages maintain constant between $4.003 \mathrm{~s}$ and 4.006s. In Scheme 3, since only part of SMs are inserted after the fault occurs, the capacitor voltages remain in the range of 0.95-1.05 p.u. The average SM capacitor voltages of each arm at $4 \mathrm{~s}$ and $4.006 \mathrm{~s}$ are shown in Table IV At 4.006s, the capacitor voltages in Scheme 3 are larger than that in Scheme 1 and 2. These simulation results prove the effect of the AFCLC on suppressing the discharge of the SM capacitors.

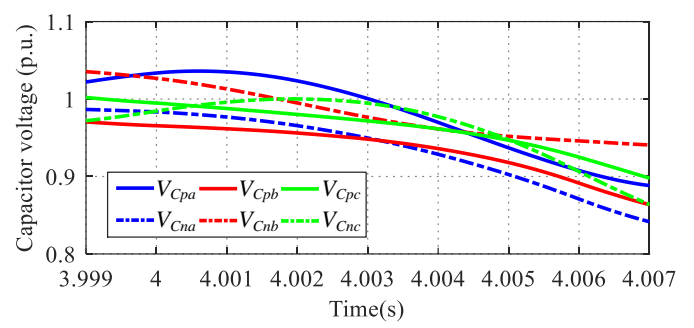

(a) No control

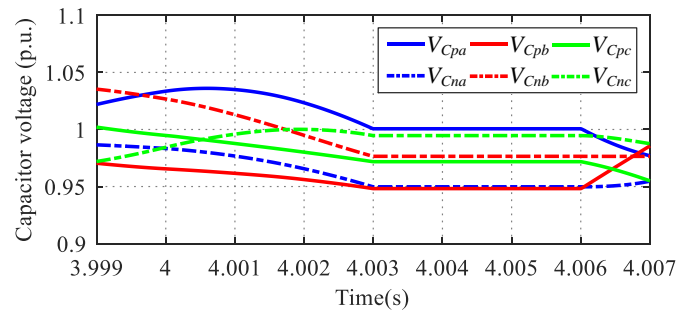

(b) Bypass

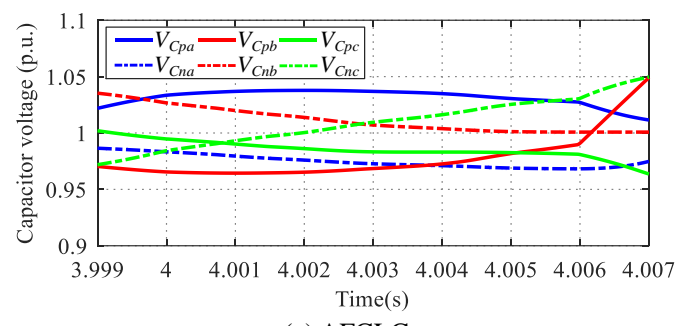

(c) AFCLC

Fig. 16 Comparison of average SM capacitor voltages of each arm in MMC2.

$\underline{\text { Table IV Average SM capacitor voltages of each arm at } 4 \mathrm{~s} \text { and } 4.006 \mathrm{~s}}$

\begin{tabular}{c||c|c|c|c}
\hline \hline Time & $4.000 \mathrm{~s}$ & \multicolumn{3}{|c}{$4.006 \mathrm{~s}$} \\
\hline Scheme & & No control & Bypass & AFCLC \\
\hline \hline$V_{C p a}$ (p.u.) & 1.034 & 0.908 & 1.001 & 1.027 \\
\hline$V_{C n a}$ (p.u.) & 0.983 & 0.871 & 0.950 & 0.968 \\
\hline$V_{C p b}$ (p.u.) & 0.966 & 0.891 & 0.948 & 0.991 \\
\hline$V_{C n b}$ (p.u.) & 1.027 & 0.946 & 0.976 & 1.001 \\
\hline$V_{C p c}$ (p.u.) & 0.995 & 0.925 & 0.971 & 0.981 \\
\hline$V_{C n c}$ (p.u.) & 0.984 & 0.906 & 0.995 & 1.031 \\
\hline \hline
\end{tabular}

\section{Comparison of AC Side Voltages}

The AC side voltages of MMC2 under different control schemes are shown in Fig. 17. In Scheme 1, since the converter does not take any current limiting methods, the AC side voltages are hardly affected. In Scheme 2, all SMs in MMC2 are bypassed after fault is detected at $4.003 \mathrm{~s}$. Hence, the AC side voltages drop sharply and even approach 0 (still have some residual inductor voltage). In Scheme 3, the AC side voltages begin to drop after the fault occurs at 4.000s. Since not all SMs are bypassed, the AC side voltage can maintain a certain level. This AC side voltage that is not completely reduced to 0 can prevent excessive $\mathrm{AC}$ current from flowing into the converter.

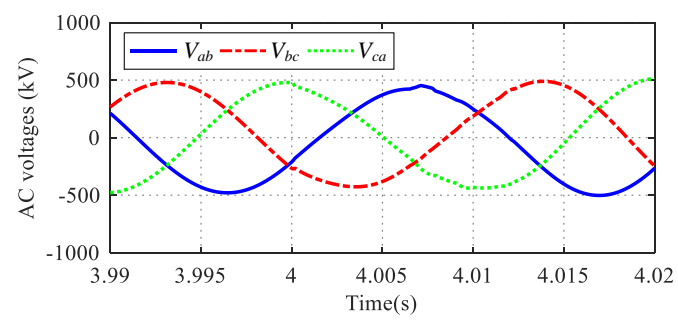

(a) No control 


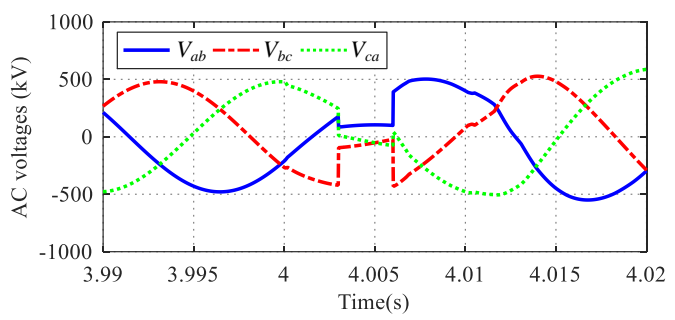

(b) Bypass

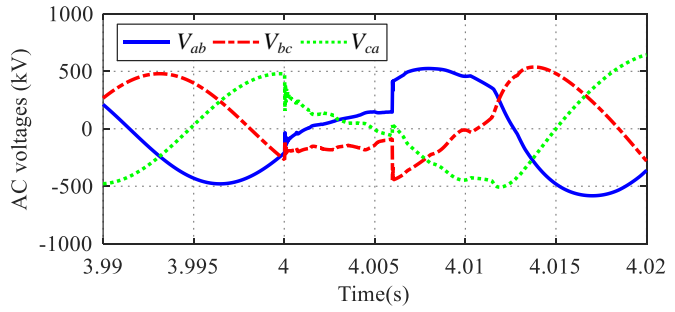

(c) AFCLC

Fig. 17 Comparison of AC side voltages in MMC2.

\section{E. Comparison of Transient Performance}

Fig. 18 shows the transmitted active power of all converters in the DC grid. In Scheme 1, the active power constantly increases until the fault current is interrupted at $4.006 \mathrm{~s}$. In Scheme 2, the power rises at the same rate before $4.003 \mathrm{~s}$ and decreases to almost 0 between 4.003 and 4.006s. In Scheme 3, the active power fluctuation is less severe compared with Scheme 1. Moreover, different from Scheme 2, the active power does not decease to 0 during fault interruption. It can be concluded that the AFCLC can reduce the active power fluctuation compared with the other schemes.

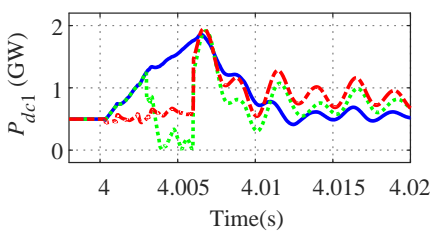

(a) Active power of MMC1

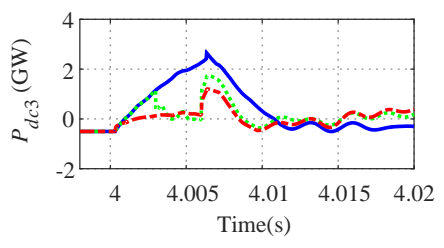

(c) Active power of MMC3

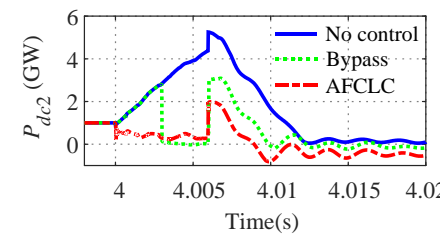

(b) Active power of MMC2

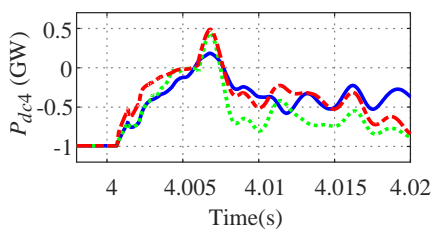

(d) Active power of MMC4
Fig. 18 Comparison of active power of all converters.

Fig. 19 shows the DC voltages of all converters in the DC grid. Since the three curves would overlap in this time scale and the comparison of Scheme 1 and 3 is more significant, the simulation results of Scheme 2 are not involved. It can be observed that the AFCLC increases the fluctuation range and prolongs the restoration of DC voltages. In Scheme 1, the DC voltage fluctuation is not severe. The restoration times of $V_{d c 1}$, $V_{d c 2}, V_{d c 4}$ are within $100 \mathrm{~ms}$, while that of $V_{d c 3}$ is about $150 \mathrm{~ms}$. In Scheme 3, the DC voltages are adaptively reduced by the AFCLC during fault to suppress the fault current. After the fault line is isolated at $4.006 \mathrm{~s}$, the DC voltages begin to recover and the maximum voltage does not exceed 1.3 p.u. The restoration times of the DC voltages are increased to $200 \mathrm{~ms}$. However, the fluctuation range of $0.2-1.3$ p.u. and the restoration time of 200 ms are still acceptable for the operation of the DC grid [23][24].

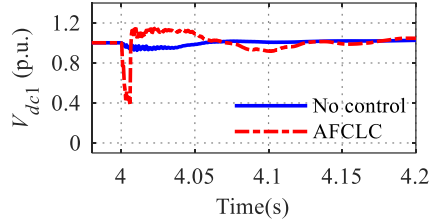

(a) Voltage of MMC1

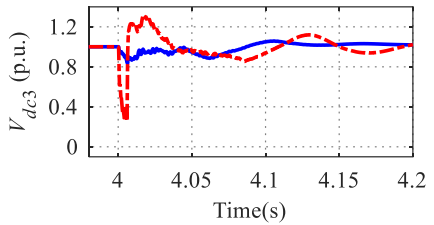

(c) Voltage of MMC3

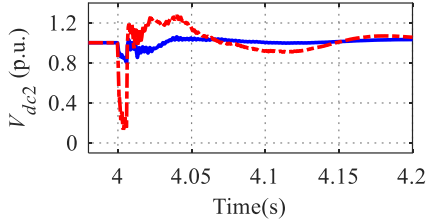

(b) Voltage of MMC2

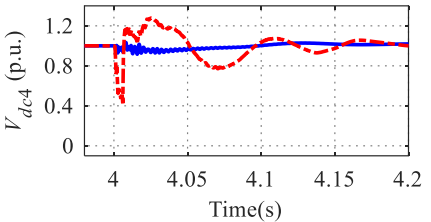

(d) Voltage of MMC4
Fig. 19 Comparison of DC voltages of all converters.

Fig. 20 shows the DC voltages and modulation factors of all converters in Scheme 3. It can be observed that both curves are identical between 4.000s and 4.006s. The decrease of $K_{M}$ can effectively reduce the DC voltages of converters. After 4.006s, the AFCLC is disabled for a period to avoid affecting the restoration of the system. According to the reclosing time of the DCCBs [8], the disable time is designed as $300 \mathrm{~ms}$.

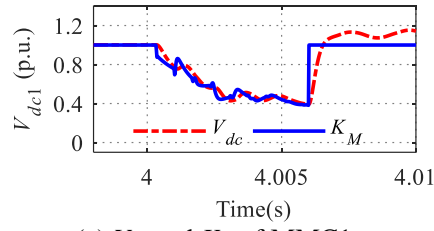

(a) $V_{d c}$ and $K_{M}$ of MMC1

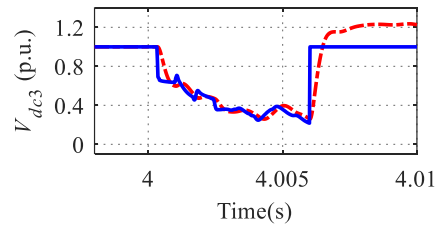

(c) $V_{d c}$ and $K_{M}$ of MMC3

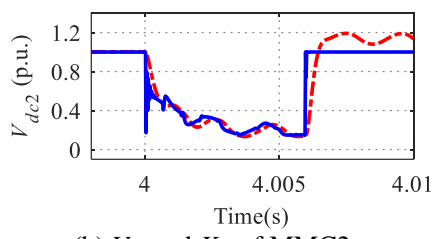

(b) $V_{d c}$ and $K_{M}$ of MMC2

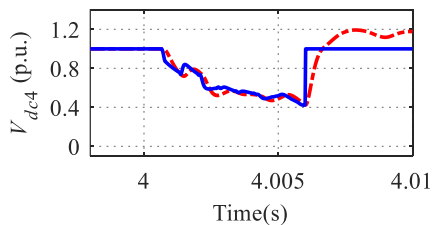

(d) $V_{d c}$ and $K_{M}$ of MMC4 Fig. 20 Comparison of DC voltages and modulation factors in Scheme 3.

Fig. 21 shows the DC currents of all converters in the DC grid. Similarly, only the simulation results of Scheme 1 and Scheme 3 are displayed for comparison. It can be observed that before the fault is isolated, the currents of MMC1 and MMC4, which are remote from the fault point, are similar in both situations. The maximum currents of MMC2 and MMC3 in Scheme 3 is significantly reduced compared to that in Scheme 1, due to the effect of the AFCLC. Since MMC2 and MMC3 are the major contributors to fault currents, this reduction results in the decrease of currents in CB23 and CB32, as shown in Fig. 14. During the restoration process, the AFCLC also increases the fluctuation range and restoration time of DC currents. The fluctuation range of $I_{d c 4}$ is of 3.3-1.8 kA in Scheme 3. In Scheme 1, the restoration times of $I_{d c 1}, I_{d c 2}, I_{d c 3}$ are $200 \mathrm{~ms}$, while that of $I_{d c 4}$ is $300 \mathrm{~ms}$. In Scheme 3 , the restoration times of DC currents are increased to $300 \mathrm{~ms}$.
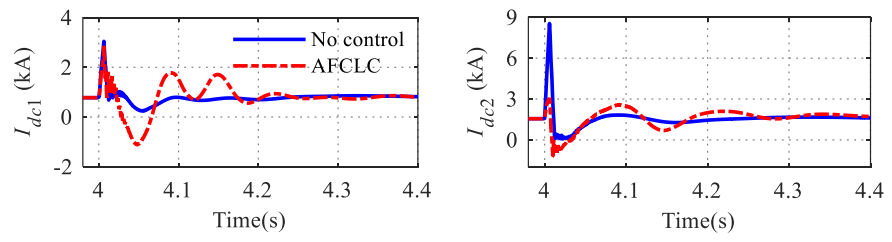
This paper is a post-print of a paper submitted to and accepted for publication in IEEE Transaction on Power Delivery and is subject to Institution of Electrical and Electronic Engineering Copyright. The copy of record is available at IEEE Xplore Digital Library

(a) Current of MMC1

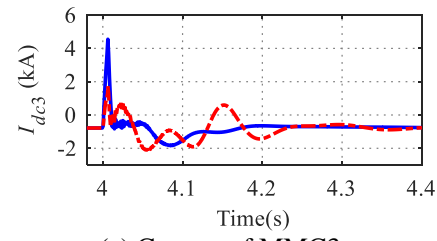

(c) Current of MMC3 (b) Current of MMC2

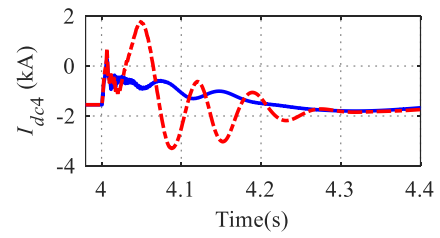

(d) Current of MMC4

Fig. 21 Comparison of DC currents of all converters.

\section{Performance Evaluation}

\section{A. Response to Change of Operating Conditions}

To prove that the proposed AFCLC would not affect the operation of the DC grid in case of operating conditions changing, a certain step change of DC power is applied in MMC2. The reference value of the active power of the MMC2 increases from $1000 \mathrm{MW}$ to $1100 \mathrm{MW}$ at $4 \mathrm{~s}$, and then decreases to $900 \mathrm{MW}$ at $5 \mathrm{~s}$. The simulation results are shown from Fig. 22 to Fig. 23.

Fig. 22 shows the DC voltages and modulation factors of all converters in case of operating conditions change. It can be observed that the lower limits of the AFCLC of all converters are no less than 0.98 p.u. Since the current change rate is unable to trigger the hysteresis comparator, the modulation factors of all converters are maintained at 1.0. These simulation results illustrate that the AFCLC does not false trigger in this situation.

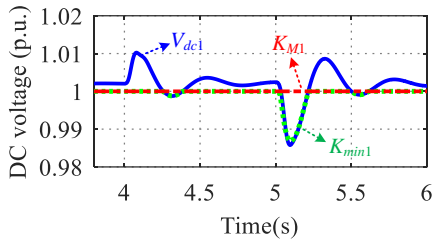

(a) $\mathrm{MMC1}$

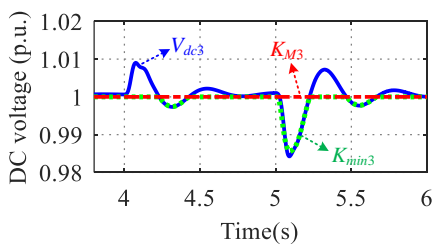

(c) $\mathrm{MMC} 3$

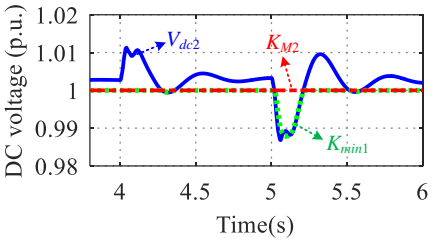

(b) $\mathrm{MMC} 2$

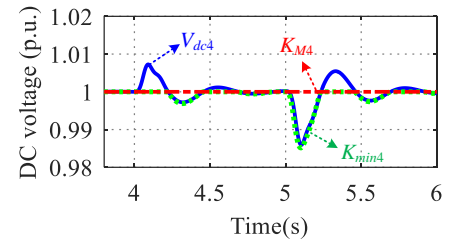

(d) $\mathrm{MMC} 4$

Fig. 22 DC voltages and modulation factors in case of operating conditions change.

Fig. 23 show the rate of change of current (ROCOC) of all converters. It can be observed that the ROCOC of all converters are less than $10 \mathrm{kA} / \mathrm{s}$. The activation threshold of the hysteresis comparator is set as half of the changing rate of the fault current $\left(V_{d c} / 4 L_{d c}=800 \mathrm{kA} / \mathrm{s}\right)$. Since the ROCOC of all converters are far smaller than this threshold, the AFCLC is not triggered in this situation.

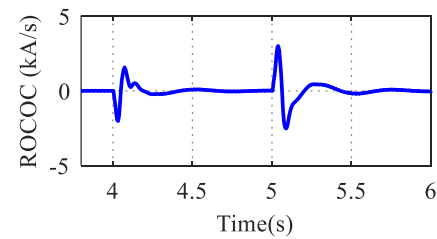

(a) MMC1

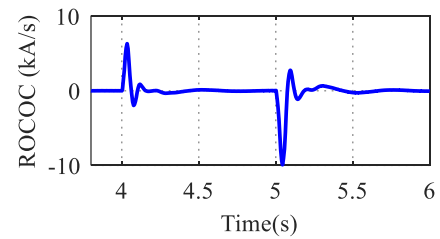

(b) $\mathrm{MMC} 2$

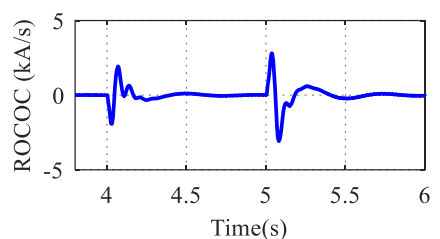

(c) MMC3

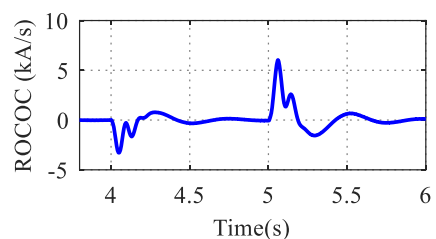

(d) MMC4

Fig. 23 ROCOC of all converters in case of operating conditions change.

\section{B. Influence on Fault Detection}

Since the proposed AFCLC operates immediately to reduce the DC voltages of converters after fault occurrence, it may interfere with the fault detection algorithms. Therefore, it is necessary to study the impact of the AFCLC on fault detection. In this paper, a fault detection method of measuring the rate of change of voltage (ROCOV), which is proposed in [11], is employed in the test system to analyze the influence of the AFCLC. The trigger threshold of fault detection is set as -2.0 $\mathrm{kV} / \mu \mathrm{s}$.

1) Faults at Overhead Line

A permanent short-circuit fault is applied at the head of overhead line $23\left(F_{L 23}\right)$ at 4 s. Fig. 24 and Fig. 25 show the ROCOV of the DC bus and line voltages. The blue solid line shows the results of the case that converters operate without any current-limiting control, while the red dash-dotted line shows the simulation results of the proposed AFCLC. It can be observed that the results are almost identical. Due to the effect of the AFCLC on reducing the DC voltage of converter, the ROCOV of DC bus voltages has a slight reduction compared with that in case of No control. The measured ROCOV exceeds $-2 \mathrm{kV} / \mu$ s only for the internal faults, i.e., the ROCOV of $V_{\text {line23 }}$ and $V_{\text {line } 32}$, as shown in Fig. 25 (c)-(d). These results indicate that the ROCOV can effectively identify internal and external faults. And the AFCLC has little effect on the ROCOV of the line and DC bus voltages.

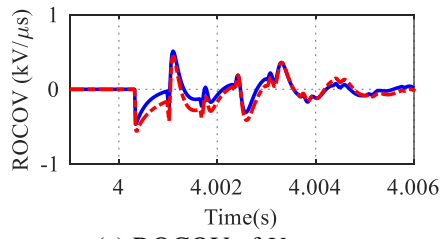

(a) ROCOV of $V_{d c b u s 1}$

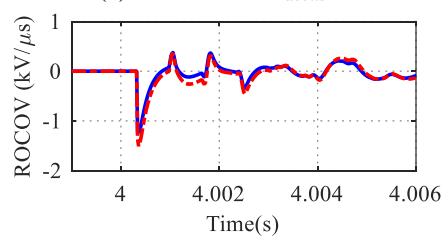

(c) ROCOV of $V_{d c b u s} 3$

Fig. 24 ROCOV of the DC bus voltages in the case of $F_{L 23}$ fault.

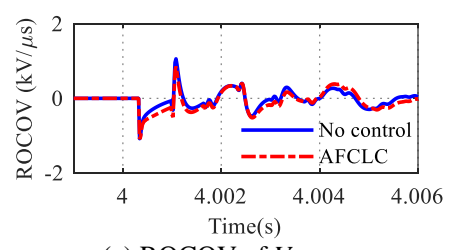

(a) ROCOV of $V_{\text {line } 12}$

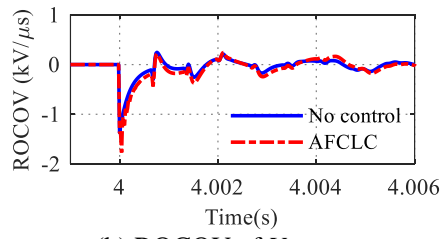

(b) ROCOV of $V_{d c b u s 2}$

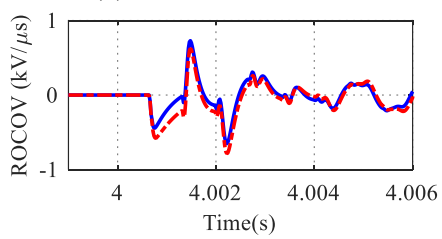

(d) ROCOV of $V_{d c b u s 4}$

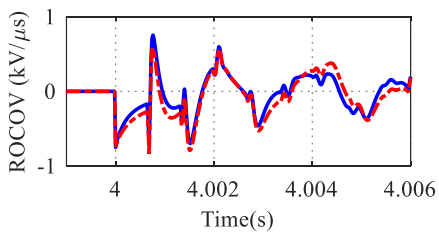

(b) ROCOV of $V_{\text {line } 21}$ 
This paper is a post-print of a paper submitted to and accepted for publication in IEEE Transaction on Power Delivery and is subject to Institution of Electrical and Electronic Engineering Copyright. The copy of record is available at IEEE Xplore Digital Library

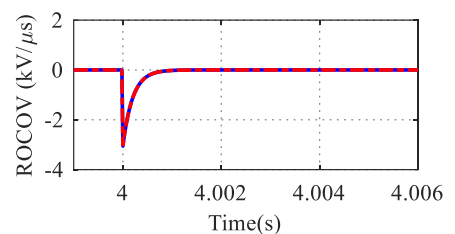

(c) ROCOV of $V_{\text {line } 23}$

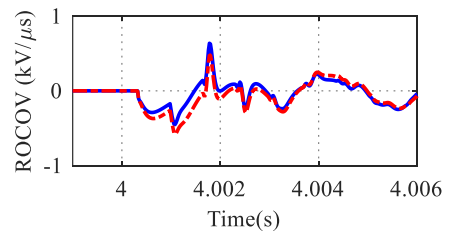

(e) ROCOV of $V_{\text {line } 34}$

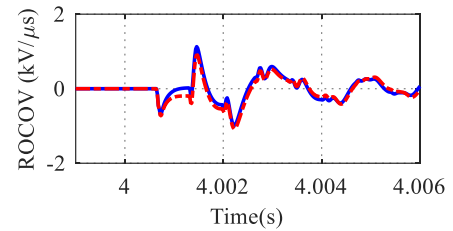

(g) ROCOV of $V_{\text {line } 41}$

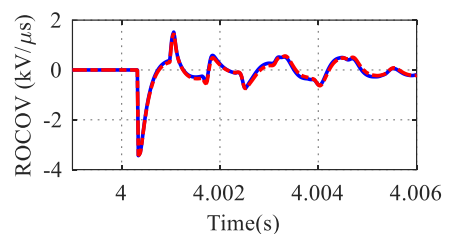

(d) ROCOV of $V_{\text {line } 32}$

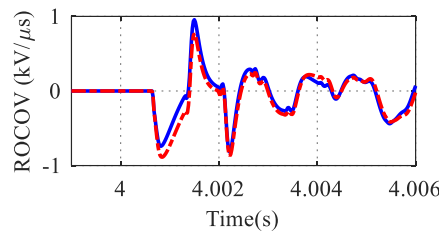

(f) ROCOV of $V_{\text {line } 43}$

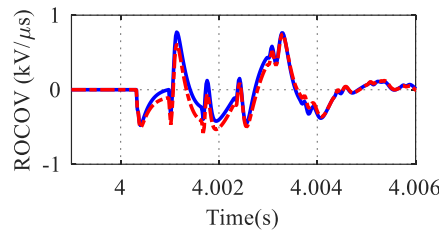

(h) ROCOV of $V_{\text {line } 14}$

Fig. 25 ROCOV of the line voltages in the case of $F_{L 23}$ fault.

2) Faults at DC Bus

A permanent short-circuit fault is applied at the DC bus of MMC2 $\left(F_{B 2}\right)$ at 4s. Fig. 26 and Fig. 27 show the ROCOV of the DC bus and line voltages. It can be observed that results under AFCLC comply well with the other. Due to the effect of the AFCLC, the ROCOV of non-fault DC buses decrease a little compared with those in case of No control. As can be seen, only the measured ROCOV of $V_{d c 2}$ exceeds $-2 \mathrm{kV} / \mu \mathrm{s}$ and all the other ROCOVs are larger than $-2 \mathrm{kV} / \mu \mathrm{s}$. These results indicate that the AFCLC will not cause false detection.

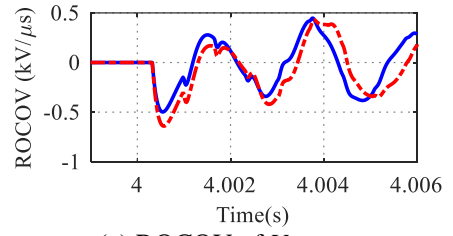

(a) ROCOV of $V_{\text {dcbus } 1}$

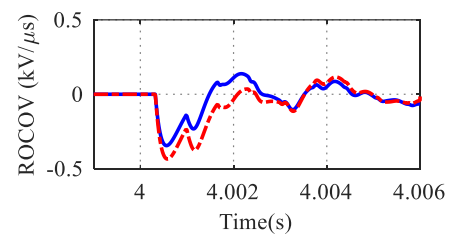

(c) ROCOV of $V_{d c b u s 3}$

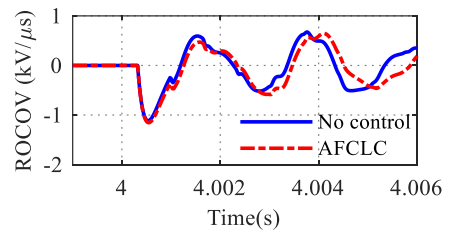

(a) ROCOV of $V_{\text {line12 }}$

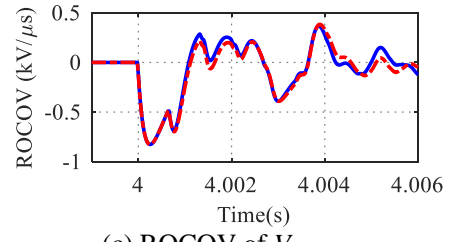

(c) ROCOV of $V_{\text {line23 }}$

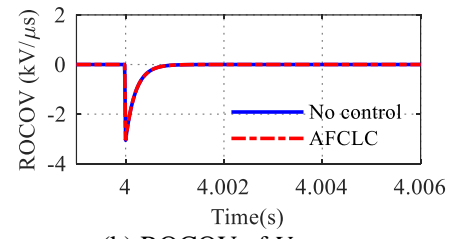

(b) ROCOV of $V_{\text {dcbus } 2}$

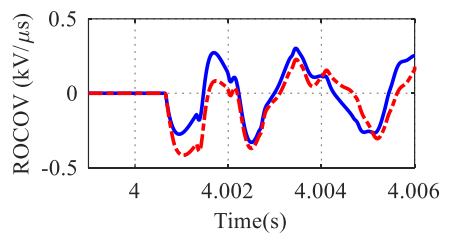

(d) ROCOV of $V_{d c b u s 4}$

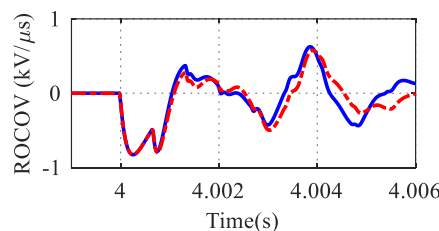

(b) ROCOV of $V_{\text {line } 21}$

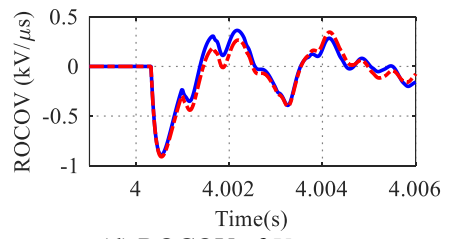

(d) ROCOV of $V_{\text {line32 }}$

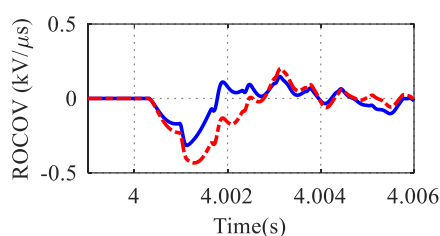

(e) ROCOV of $V_{\text {line34 }}$

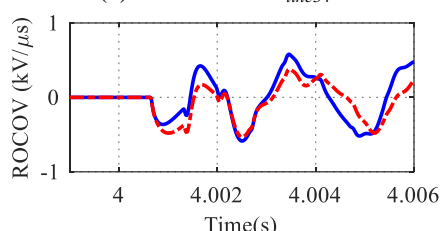

(g) ROCOV of $V_{\text {line } 41}$

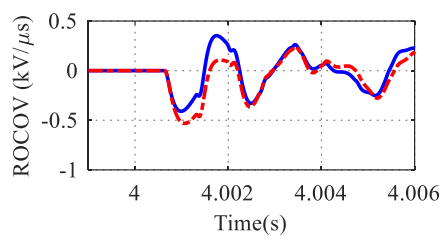

(f) ROCOV of $V_{\text {line } 43}$

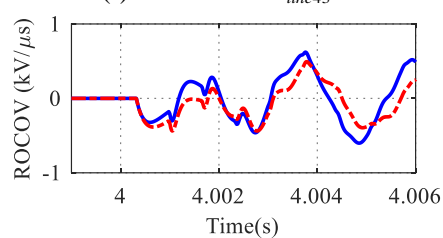

(h) ROCOV of $V_{\text {line } 14}$

Fig. 27 ROCOV of the line voltages in the case of $F_{B 2}$ fault.

\section{CONCLUSION}

This paper proposes an adaptive fault current limiting control to limit the fault current of HB-MMC without adding supplementary devices. This control scheme can adaptively reduce the voltages of MMC to limit the fault current according to different fault conditions. The AFCLC is triggered immediately once a fault occurs and its activation is independent of the DC fault protection system. The theoretical analysis of the AFCLC verifies its effect on fault current limiting and reducing the current rise rate. It is also shown that increasing the parameters of the AFCLC means a better effect on suppressing fault current.

A four-terminal HB-MMC DC grid is simulated to further investigate the effectiveness of proposed AFCLC. The simulation results under DC short-circuit fault shows that compared with normal control, the AFCLC can reduce the interrupted current and energy absorption of a DCCB from $10.39 \mathrm{kA}$ and $38.24 \mathrm{MJ}$ to $4.62 \mathrm{kA}$ and $8.32 \mathrm{MJ}$, respectively. Besides, the AFCLC also has the advantage of preventing overcurrent in arms during the fault. The simulation results of operating conditions changing validate that the AFCLC would not be falsely triggered under normal operation. The comparisons of ROCOVs between the normal control and the AFCLC shows that the AFCLC will not affect the fault detection accuracy under DC faults.

\section{REFERENCES}

[1] O. D. Adeuyi, M. Cheah-Mane, J. Liang, N. Jenkins, "Fast Frequency Response from Offshore Multi-terminal VSC-HVDC Schemes," IEEE Trans. Power Del., vol. 32, no. 6, pp. 2442-2452, Dec. 2017.

[2] A. A. Elserougi, A. S. Abdel-Khalik, A. M. Massoud, and S. Ahmed, "A new protection scheme for HVDC converters against dc-side faults with current suppression capability," IEEE Trans. Power Del., vol. 29, no. 4, pp. 1569-1577, Aug. 2014.

[3] J. Beerten, S. Arco, and J. Suul, "Identification and small-signal analysisof interaction modes in VSC MTDC systems," IEEE Trans. Power Del., vol. 21, no. 2, pp. 888-897, Apr. 2016.

[4] Y. Li, G. Tang, J. Ge, et al., "Modeling and Damping Control of Modular Multilevel Converter Based DC Grid," IEEE Trans. on Power Syst., vol. 33, no. 1, pp. 723-735, Jan. 2018.

[5] C. M. Franck, "HVDC circuit breakers: A review identifying future research needs," IEEE Trans. Power Del., vol. 26, no. 2, pp. 998-1007, Apr. 2011.

[6] O. Cwikowski et al., "Fault current testing envelopes for VSC HVDC circuit breakers," IET Gener., Transmiss., Distrib., vol. 10, no. 6, pp. 1393-1400, 2016.

[7] G. Tang, G. Wang, Z. He, H. Pang, X. Zhou, Y. Shan, Q. Li, "Research on key technology and equipment for Zhangbei $500 \mathrm{kV}$ DC grid", High 
This paper is a post-print of a paper submitted to and accepted for publication in IEEE Transaction on Power Delivery and is subject to Institution of Electrical and Electronic Engineering Copyright. The copy of record is available at IEEE Xplore Digital Library

Voltage Eng., vol. 44, no. 7, pp. 2097-2106, Jul. 2018

[8] G. Tang, G. Pang, and Z. He. "Research on key technology and equipment for Zhangbei 500kV DC Grid," in Proc. Int. Power Electron. Conf., 2018, pp. 2343-2351.

[9] "Zhangbei flexible HVDC project starts product bidding", [Online]. Avai lable: http://pg.jrj.com.cn/acc/Res/CN_RES/INDUS/2018/4/1/79e33f5342ec-473a-8e9f-4a390c398071.pdf

[10] M. Callavik, A. Blomberg, J. Hafner, and B. Jacobson, "The hybrid HVDC breaker: an innovation breakthrough enabling reliable HVDC grids", ABB Grid Systems, Technical Paper, Nov. 2012.

[11] J. Sneath and A. D. Rajapakse, "Fault detection and interruption in an earthed HVDC grid using ROCOV and hybrid DC breakers," IEEE Trans. Power Del., vol. 31, no. 3, pp. 973-981, Jun 2016.

[12] W. Wang, M. Barnes, O. Marjanovic, and O. Cwikowski, "Impact of dc breaker systems on multiterminal VSC-HVDC stability", IEEE Trans. Power Deliv., vol. 31, no. 2, pp. 769-779, Mar. 2016.

[13] D. M. Larruskain, I. Zamora, O. Abarrategui, and A. Iturregi, "A solidstate fault current limiting device for VSC-HVDC systems," International Journal of Emerging Electric Power Systems, vol. 14, no. 5, Jan 2013.

[14] Q. Yang, et al., "Design and application of superconducting fault current limiter in a multiterminal HVDC system", IEEE Trans. Appl. Supercond., vol. 27, no. 4, pp. 1-5, June 2017.

[15] S. Cui, S. Sul, "A Comprehensive DC Short-Circuit Fault Ride Through Strategy of Hybrid Modular Multilevel Converters (MMCs) for Overhead Line Transmission," IEEE Trans. Power Electron., vol. 31, no. 11, pp. 7780-7796, Nov. 2016.

[16] W. Lin, D. Jovcic, S. Nguefeu, and H. Saad, "Full bridge MMC converter optimal design to HVDC operational requirements," IEEE Trans. Power Del., vol. 31, no. 1, pp. 1342-1350, Jun. 2016.

[17] W. Xiang, W. Lin, L. Xu, J. Wen, "Enhanced independent pole control of hybrid MMC-HVDC system," IEEE Trans. Power Del., vol. 33, no. 2, pp. 861-872, Apr. 2018.

[18] M. Zhou, W. Xiang, W. Zuo, et al., "Active Current-Limiting Control to Handle DC Line Fault of Overhead DC Grid," 2019 10th International Conference on Power Electronics and ECCE Asia (ICPE 2019 - ECCE Asia), Busan, Korea (South), 2019, pp. 1-6.

[19] D. Jovcic, W. Lin, S. Nguefeu and H. Saad, "Low-Energy Protection System for DC Grids Based on Full-Bridge MMC Converters," IEEE Trans. Power Del., vol. 33, no. 4, pp. 1934-1943, Aug. 2018.

[20] J. Xu, X. Zhao, H. Jing, J. Liang, C. Zhao, "DC Fault Current Clearance at the Source Side of HVDC Grid Using Hybrid MMC," IEEE Trans. Power Del, vol. 35, no. 1, pp. 140-149, Feb. 2020.

[21] M. K. Bucher and C. M. Franck, "Contribution of fault current sources in multiterminal HVDC cable networks", IEEE Trans. Power Del., vol. 28, no. 3, pp. 1796-1803, May 2013.

[22] R. Dantas, J. Liang, C. E. Ugalde-Loo, A. Adamczyk, C. Barker, and R. Whitehouse, "Progressive Fault Isolation and Grid Restoration Strategy for MTDC Networks," IEEE Trans. Power Del., vol. 33, no. 2, pp. 909-918, April 2018.

[23] S. Wang, C. Li, O. D. Adeuyi, G. Li, C. E. Ugalde-Loo and J. Liang, "Coordination of MMCs With Hybrid DC Circuit Breakers for HVDC Grid Protection," IEEE Trans. Power Del., vol. 34, no. 1, pp. 11-22, Feb. 2019.

[24] X. Li, B. Zhao, Y. Wei, X. Xie, Y. Hu, D. Shu. "DC fault current limiting effect of MMC submodule capacitors." International Journal of Electrical Power \& Energy Systems, vol. 115, no. 105444, Feb. 2020

[25] S. Yang, W. Xiang, X. Lu, W. Zuo and J. Wen, "An Adaptive Reclosing Strategy for MMC-HVDC Systems with hybrid DC Circuit Breakers," IEEE Trans. Power Del. doi: 10.1109/TPWRD.2019.2935311

[26] T. An, G.Tang, W.Wang, "Research and application on multi-terminal and DC grids based on VSC-HVDC technology in China," High Voltage, pp. 1-10, Feb. 2017.

[27] W. Xiang, S. Yang, L. Xu, et al, "A Transient Voltage based DC Fault Line Protection Scheme for MMC based DC Grid Embedding DC Breakers," IEEE Trans. Power Del., vol. 34, no. 1, pp. 334-345, Feb. 2019.

\section{BIOGRAPHIES}

Binye Ni received his B.Eng. degree in electrical engineering from Huazhong University of Science and Technology (HUST), Wuhan, China, in 2017. He is currently working toward the Ph.D. degree at HUST. His research interests include HVDC control and protection, dc circuit breaker and dc grids.

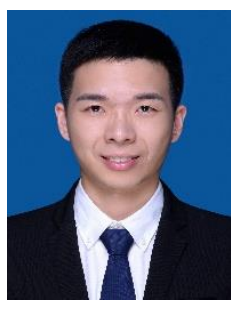

Wang Xiang (S'16-M'17) received his B.Eng. and $\mathrm{PhD}$ degrees both in electrical engineering from Huazhong University of Science and Technology (HUST), China in 2012 and 2017 respectively. He was a visiting student at the University of Aberdeen and the University of Strathclyde in 2014 and 2016 respectively. Currently, he is a research associate with the University of Strathclyde since 2018. His main research interests include MMC-HVDC, high power $\mathrm{dc} / \mathrm{dc}$ converters and $\mathrm{dc}$ grids.

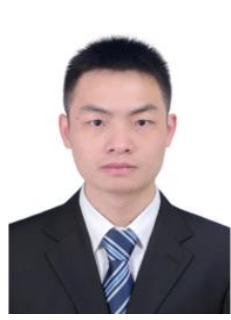

Meng Zhou was born in Hunan, China, in 1987. He received the $\mathrm{Ph}$.D. degree in electrical engineering from the School of Electrical and Electronic Engineering, Huazhong University of Science and Technology, Hubei, China, in 2019. He is currently a Postdoctoral Researcher with the School of Electrical and Electronic Engineering, Huazhong University of Science and Technology. His current research interests include voltage-source converter-HVdc and dc circuit breaker.

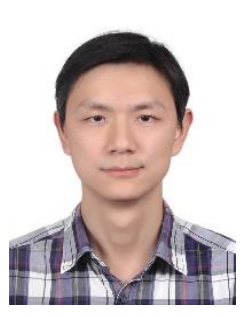

Wenping Zuo received the B.S. degree and Ph.D degree in electrical engineering from Huazhong University of Science and Technology (HUST), Wuhan, China, in 2009 and 2017, respectively. Currently he is a Post-Doctoral Research Fellow with HUST. His research interests include DC grid key equipment, energy storage, and renewable energy integration.

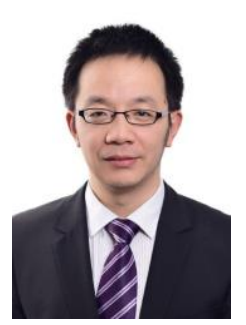

Wei Yao (M'13-SM'17) received the B.S. and Ph.D. degrees in electrical engineering from Huazhong University of Science and Technology (HUST), Wuhan, China, in 2004 and 2010, respectively. He was a Post-Doctoral Researcher with the Department of Power Engineering, HUST, from 2010 to 2012 and a Postdoctoral Research Associate with the Department of Electrical Engineering and Electronics, University of Liverpool, Liverpool, U.K., from 2012 to 2014. Currently, he has been an Associate Professor with the School of Electrical and Electronics Engineering, HUST, Wuhan, China. His current research interests include power system stability analysis and control, renewable energy, HVDC and DC Grid, and application of artificial intelligence in Smart Grid.

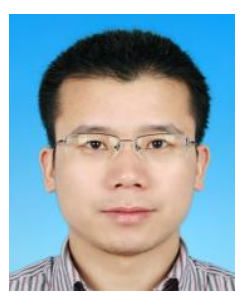

Weixing Lin (M'13) obtained his B.E. and PhD degrees in electrical engineering from Huazhong University of Science and Technology (HUST), China, in 2008 and 2014 respectively. He is currently the director of HVDC department at TBEA China Xinjiang Sunoasis Co. Ltd. His research interests lie in HVDC, MMC, dc-dc autotransformer, high power and dc grids.

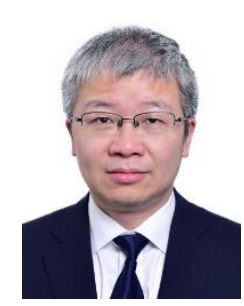

Jinyu Wen (M'10) received his B.Eng. and Ph.D. degrees all in electrical engineering from Huazhong University of Science and Technology (HUST), Wuhan, China, in 1992 and 1998, respectively. He was a visiting student from 1996 to 1997 and research fellow from 2002 to 2003 all at the University of Liverpool, UK, and a senior visiting researcher at the University of Texas at 
This paper is a post-print of a paper submitted to and accepted for publication in IEEE Transaction on Power Delivery and is subject to Institution of Electrical and Electronic Engineering Copyright. The copy of record is available at IEEE Xplore Digital Library

Arlington, USA in 2010. From 1998 to 2002 he was a director engineer in XJ Electric Co. Ltd. in China. In 2003 he joined the HUST and now is a Professor at HUST. His current research interests include renewable energy integration, energy storage application, DC grid, and power system operation and control. 